Claremont Colleges

Scholarship@ Claremont

Pomona Faculty Publications and Research

Pomona Faculty Scholarship

$1-1-2012$

\title{
Changes Across 25 Years of Statistics in Medicine
}

Johanna S. Hardin

Pomona College

\section{Recommended Citation}

Hardin, J. Changes Across 25 Years of Medicine, Chance, 25: 35-37; 2012.

This Article is brought to you for free and open access by the Pomona Faculty Scholarship at Scholarship @ Claremont. It has been accepted for inclusion in Pomona Faculty Publications and Research by an authorized administrator of Scholarship @ Claremont. For more information, please contact scholarship@cuc.claremont.edu. 


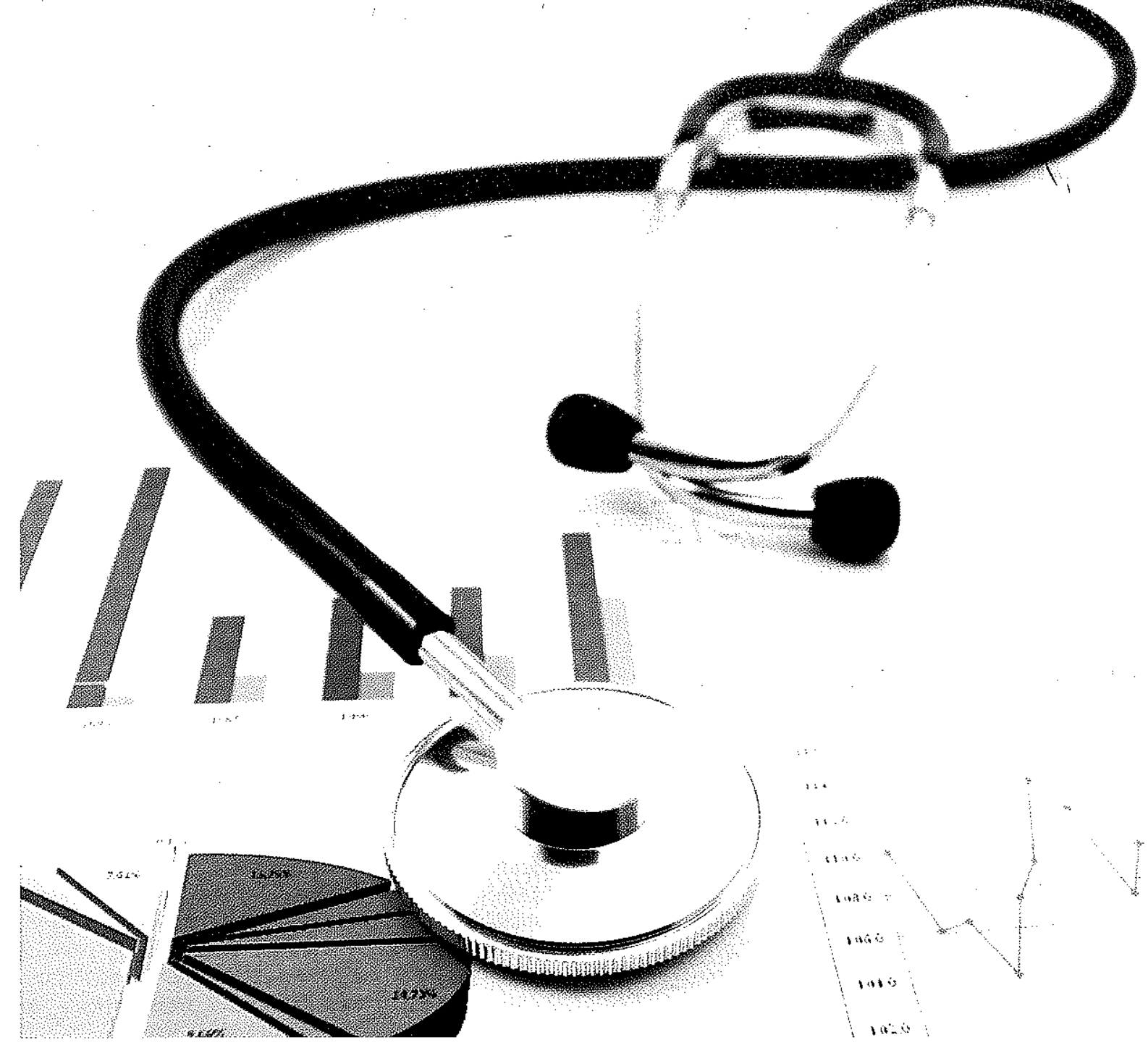

\section{Changes Across 25 Years of Statistics in Medicine}

Johanna Hardin

In light of the CHANCE special issue on the culture of statistics in medicine, we asked senior members of the medical community to comment about their experience with statistics over the past 25 years. Statisticians have made substantial progress in working with medical researchers, practitioners, and public health workers; doctors are reporting that statistics is integrated into almost every aspect of medical analysis. However, there is also a sense that sophisticated statistics are needed to answer complex medical questions. Not all clinicians are trained to understand the results from such studies, and not all researchers see the fruitfulness associated with collaborations with statisticians. The perspectives included in the interviews on the following pages belp direct us, as statisticians, toward continued partnership in answering important medical and public health questions. 


\section{JEFFERY M. DRAZEN}

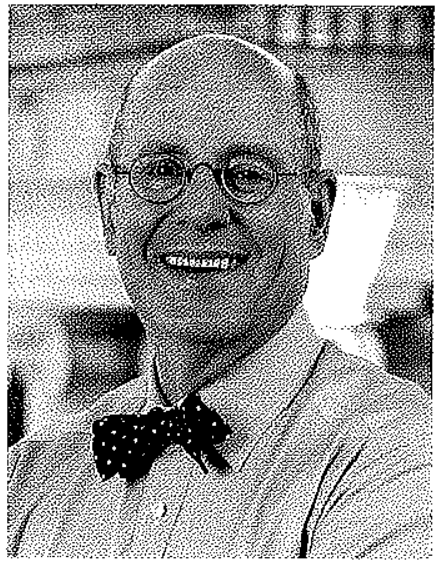

Jeffery $M$. Drazen is the Distinguished Parker B. Francis Professor of Medicine at Harvard Medical School, professor of physiology at the Harvard School of Public Health, and a senior physician af Brigham and Women's Hospital. He is also editor-in-chief of The New England Journal of Medicine.
[In the] early 1900s, most of what was published by The Nerw England Journal of Medicine (NEJM) was case series that showed big effects. Now that the effect sizes resulting from different diagnostic or treatment approaches are smaller, we have to worry more about variability in patients studied and their outcomes. To identify smaller effect sizes and subpopulation effects, we need statistics to go hand-in-hand with the clinical research.

In the last decade, research methods have become more sophisticated. Currently, good science uses state-of-the-art statistics; it must be part of the experimental plan and best research practices. The NEJM has four statisticians on staff as part of their core editorial group. The statisticians-or biostatisticianshave expertise in genetics, epidemiology, or experimental design.

Statistics has become more important in medical education. Harvard has a first-year class that provides medical students with information about how to read the literature. $N E J M$ also teaches two classes a year on understanding the peer-reviewed literature; a substantial fraction of the course is about experimental design and statisti$\mathrm{cal}$ inference. It is not possible to read the medical literature without some understanding of the statistical methods used within.

Twenty-five years ago, it was not uncommon for a statistician to become involved in a research project only after the data were collected. Today, the statistician needs to be involved at the onset of the project. For example, in putting together a clinical trial network. funded by the National Institutes of Health, there is competition for both clinical and data analysis sites.

Presently, sound statistical design is considered to be paramount to good experimentation. Statisticians need to be part of any first-class experimental team. Without statistics, experiments can be unrecoverable.

\section{ROBERT B. LIVINGSTON}

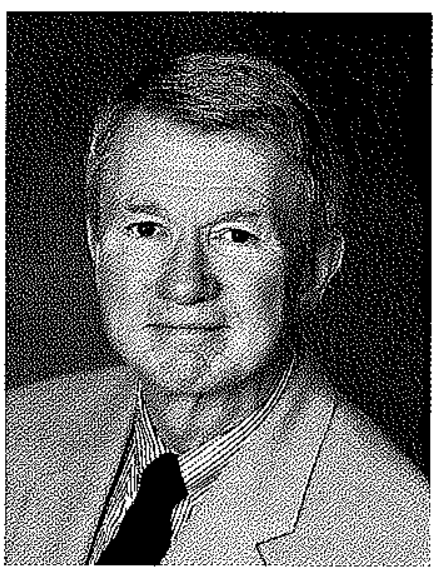

Robert $B$. Livingston is professor of medicine and hematologic oncology af the University of Arizona Cancer Center. Additionally, he chairs the lung committee for the Southwest Oncology Group, a National Cancer Institute-supported cancer clinical frials cooperative group.
Statistics is absolutely crucial to the science of clinical trials, on which all of us must rely who are trying to improve the results of cancer treatment. Over the last 25 years, there is a much greater awareness that the gold standard to adopt new therapies is an appropriately designed randomized trial. Unfortunately, the training of young medical oncologists is still short on lectures and other material that provides a genuine understanding of how studies are designed and analyzed, so that an appreciation of the value of statistics and the randomized trial is often not matched by an ability to judge whether a given design is appropriate in a particular situation (e.g., when is a phase II randomized trial inappropriate?).

In the setting of clinical cooperative groups like the Southwest Oncology Group, the statistician is both a collaborator (should we do this?) and a consultant (how should we do this?). In the setting of individual institutional trials, at least for medical oncologists, I would say that the statistician is usually a consultant. Either way, we can't do without them. 


\section{- JONATHAN E. FIELDING}

Statistics is essential in our work. At the broadest level, we need statistics to determine what our priority needs are for public health; whether the trends of health, risk factors, illness, and injury are getting better or worse; and what is the preventable burden of disease and injury. Statistics is also essential to consider the health disparities between populations. Both what we generate ourselves-from surveys and other forms of surveillance - and what we get from other sources are essential.

Also, we are a big county [Los Angeles County], and we need statistics to understand problems and associations sociodemographically by area, city, race, ethnicity, etc. Statistics is thus a core resource that helps us prioritize and informs key decisions about the best approaches to protect and promote health as well as prevent disease and injury.

The availability of these statistics has increased significantly over the past 25 years, including more national, state, and local surveys and public polling data. Examples of surveys we use are our own LA Health Survey, the California Health Interview Survey, and the Behavioral Risk Factor Surveillance System. Students are taught that analysis of data is an essential skill. The public is also more interested in statistics, although their appreciation for how to interpret statistics, especially probabilities, is quite limited in public health.

I work primarily with biostatisticians-as collaborators and consultants-on research projects to estimate the health effects of alternative policies and programs and in efforts to develop valid future forecasts of health and disease. I have worked with statisticians over the past 30 years and always learned something from the interaction; biostatisticians are an essential part of a team, either as a collaborator or consultant.

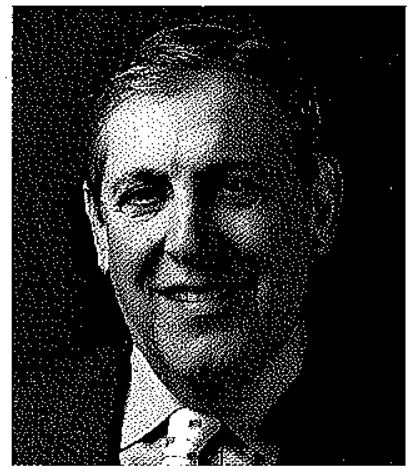

Jonathan E. Fielding is the director of the Los Angeles County Department of Public Health. He is also professor of health services and pediatrics in the school of public health at the University of California at Los Angles and co-director of the UCLA Center for Healthier Children, Families, and Communities.

\section{JAMES H. WARE}

I have occasionally been asked to compare contemporary statistical practice in the medical literature to statistical practice in the $1970 \mathrm{~s}$ and 1980s. Those comparisons consistently show how very limited the statistical methods were in the articles published in the earlier period and how much the complexity of statistical work had increased over 25 years or so. That trajectory continues today, with increasingly large studies, increasingly complex data (e.g., biomarkers, genetics, imaging), and more sophisticated statistical procedures making their way into the literature.

Given these trends, young clinical investigators need advanced training in biostatistics and study design. That training has become a huge enterprise at Harvard, with literally hundreds of fellows and junior faculty taking advanced courses every year. As a result of such training at Harvard and other academic health centers, young investigators know much more about statistics than was the case 20 years ago.

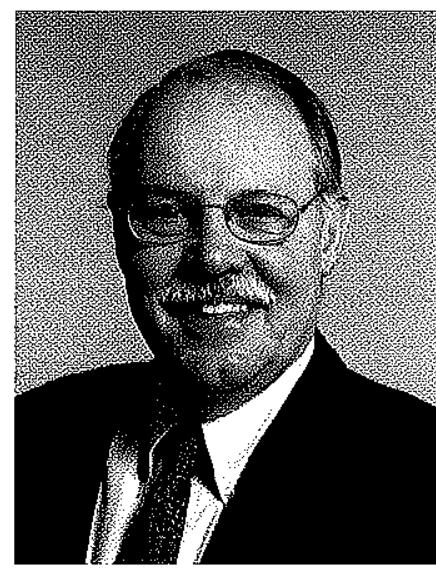

James $\mathrm{H}$. Ware is Frederick Mosteller Professor of Biostatistics and associate dean for clinical and translational science af Harvard

School of Public Health. He also serves on the editorial board of The New England Journal of Medicine as statistical consultant. 